\title{
Atendimento a MÃes de VÍtimas \\ DE ABUSO SEXUAL E ABUSADORES: CONSIDERAÇÓES TEÓRICAS E PRÁTICAS ${ }^{I}$
}

\author{
Débora Dalbosco Dell'Aglio* \\ Andreina Moura** \\ Samara Silva dos Santos ${ }^{* * *}$
}

\section{Resumo}

O objetivo deste artigo foi levantar informaçóes sobre o atendimento psicológico prestado às mães de crianças e adolescentes vítimas de abuso sexual, bem como aos autores dessa violência. A literatura mostra a importância de incluir familiares não abusivos no tratamento da vítima, tendo em vista seu envolvimento na situação. Além disso, aponta que a discussão sobre o atendimento psicológico aos perpetradores também é necessário para que se possa intervir no ciclo da violência, prevenindo novas vítimas. Por fim, são discutidos os sentimentos de mães e perpetradores frente à revelação do abuso, objetivos do tratamento em cada caso e os aspectos psicológicos relacionados. São também apresentados alguns estudos nacionais e internacionais sobre experiências de tratamentos e algumas dificuldades práticas para o andamento dos tratamentos e para se realizar estudos sobre essa temática, sobretudo no Brasil.

Palavras-chave: abuso sexual infantil; violência; atendimento psicossocial.

\footnotetext{
* Psicóloga, mestre e doutoranda do Programa de Pós-Graduação em Psicologia da Universidade Federal do Rio Grande do Sul (UFRGS).

** Psicóloga, mestre e doutoranda do Programa de Pós-Graduação em Psicologia da Universidade Federal do Rio Grande do Sul (UFRGS).

***Psicóloga e professora do Programa de Pós-Graduação em Psicologia da Universidade Federal do Rio Grande do Sul (UFRGS).
} 


\begin{abstract}
TREATMENT OF MOTHERS OF SEXUAL ABUSE VICTIMS AND ABUSERS: THEORETICAL AND PRACTICAL CONSIDERATIONS

The aim of this article was to gather information about the psychological care provided to mothers of children and adolescent victims of sexual abuse and the perpetrators of such violence. The literature demonstrates the importance of including non abusive relatives in the treatment of victims, due to their involvement with the situation. Discussing psychological support to the perpetrators is also necessary to intervene in the cycle of violence, preventing new victims. The paper focuses on the feelings of mothers and perpetrators at the moment of the abuse disclosure, the goals of the provided care in each case, and related psychological aspects. It also presents some national and international studies that report the experiences of these processes. Some practical barriers in the progress of the psychological care, as well as the difficulties of conducting studies on this topic, especially in Brazil, are reported.

Keywords: child sexual abuse; violence; psychosocial treatment.
\end{abstract}

\title{
INTRODUÇÃo
}

O objetivo deste artigo foi levantar informaçóes sobre o atendimento psicológico prestado às mães de crianças e adolescentes vítimas de abuso sexual, bem como aos autores desse tipo de violência. No Brasil, há carência na sistematização de dados sobre o atendimento psicológico a estes dois tipos de público. Esta lacuna reverbera na ausência de relatos das intervençôes utilizadas e de dados sobre sua efetividade e eficácia.

Segundo a World Health Organization (WHO) (Krug, Dahlberg, Mercy, Zwi, \& Lozano, 2002), o abuso sexual praticado contra crianças e adolescentes envolve açôes de conteúdo sexual praticadas por pessoas que se encontram num estágio de desenvolvimento e maturidade superior ao da criança ou adolescente vítima. Essas práticas sexuais podem ser de natureza heterossexual ou homossexual e são impostas à vítima por meio de coação ou indução da sua vontade. Geralmente, a pessoa que pratica tais atos não utiliza a violência física, mas seu poder de influência sobre a vítima, que não está apta a consentir. Esse tipo de violência é considerado um problema de saúde pública pela frequência com que ocorre e, principalmente, pelo impacto das repercussóes cognitivas e psicossociais que pode acarretar às vítimas e seus familiares. Desta forma, é necessário discutir alternativas de atendimento psicológico e social não apenas às crianças e adolescentes vítimas, mas também às mães ou cuidadores e, inclusive, ao autor da violência, na tentativa náo apenas de tratar as situaçôes já presentes em decorrência dos abusos, mas também de evitar que novos casos possam ocorrer.

Psic. Clin., Rio de Janeiro, vol.23, N.2, P.53 - 73, 20 II 
O Brasil ainda não apresenta indicadores precisos sobre essa violência e, portanto, não mantém estatísticas oficiais sobre casos notificados de violência intrafamiliar contra crianças e adolescentes (Martins \& Jorge, 2009). Entretanto, segundo dados disponibilizados pelo Disque 100, que é uma ferramenta social de enfrentamento à violência contra crianças e adolescentes, de 2003 a 2009 houve um aumento significativo no número de registros do abuso sexual e da exploração sexual. Estes obtiveram percentuais de 58,55\% e 39,78\%, respectivamente, sendo que, em relação ao abuso sexual, $79 \%$ das denúncias envolviam meninas e $21 \%$ meninos (Costa, Souza, Castanha, \& Lima, 2009). Os dados a respeito da vitimização sexual de crianças e adolescentes disponíveis são resultado de pesquisas que procuraram mapear essa realidade, revelando que o abuso sexual ocorre com uma frequência maior em meninas, dentro do seu ambiente familiar (Araújo, 2002; Faleiros, 2003; Habigzang, Koller, Azevedo, \& Machado, 2005).

Logo, a avaliação do funcionamento familiar é de suma importância em todo o processo que envolve a revelaçáo do abuso sexual (Machado, 2008) e deve continuar ao longo do atendimento realizado à vítima, pois possibilita um acompanhamento das reaçóes familiares e do apoio oferecido à criança. Estudos sobre as características familiares em situaçóes de abuso sexual intrafamiliar destacam que é frequente a presença de assimetria e hierarquia dessas relaçôes, evidenciando desigualdade e relações de subordinação, expressas por meio do poder dos pais sobre os filhos e do homem sobre a mulher (Koller \& De Antoni, 2004; Pelisoli \& Dell'Aglio, 2007; Santos \& Dell'Aglio, 2007). Não é raro encontrar, nestas famílias, relatos de açôes que caracterizam negligência, violência física e psicológica, uso ou abuso de drogas e dificuldade de comunicação entre os membros (Habigzang et al., 2005). A revelaçáo do abuso sexual, principalmente quando o agressor é alguém da família ou do convívio familiar, pode gerar uma crise, acionando dinâmicas de culpabilização e vergonha, que podem potencializar a sintomatologia da criança ou adolescente vítima (Machado, 2008). A revelação também possibilita, algumas vezes, a identificação do autor dos abusos sexuais, permitindo um trabalho de prevenção desse tipo de violência, pois pode haver a possibilidade de tratamento psicológico para o abusador. O engajamento no tratamento poderia impedir que este indivíduo viesse a cometer novos atos abusivos.

\section{Atendimento Às MÃEs de vítimas de ABUSO SEXUAL}

As mães de crianças e adolescentes vítimas de abuso sexual são importantes em todo o processo: no momento da revelação, da notificação e no acompanhamento 
ou atendimento psicológico das vítimas. Geralmente, as mães são as primeiras a tomarem conhecimento da situação de abuso e a forma com que lidam com essa situação influencia o prognóstico de seus filhos (Elliot \& Carnes, 2001; Pintello \& Zuravin, 2001). As mães podem reagir: (a) de forma positiva, quando acreditam no relato de seus filhos; (b) de forma negativa, quando não acreditam e mantêmse ao lado do abusador; (c) ou ambivalente, quando se encontram divididas entre o relato de seus filhos e do abusador (Santos \& Dell'Aglio, 2009). Em casos de abuso sexual intrafamiliar, por serem mães das vítimas e filhas, irmãs, cunhadas ou companheiras dos abusadores, muitas vezes se veem diante de conflitos familiares e de importantes tomadas de decisóes que podem ocasionar alteraçóes na dinâmica familiar (Furniss, 2002).

Assim, em meio a este cenário, as mães podem se sentir desassistidas, desamparadas e confusas, necessitando de orientação e acompanhamento. Costa, Almeida, Ribeiro e Penso (2009), numa reflexão sobre grupos multifamiliares como espaço para escuta, destacaram alguns sentimentos presentes nas famílias encaminhadas para atendimento: tristeza, vergonha, angústia, falta de proteção e apoio, medo e preocupação. O estudo de Carvalho, Galvão e Cardoso (2009), que investigou a percepção de máes face ao abuso sexual de suas filhas, enfatizou o sentimento de impotência verbalizado pelas mães por não terem conseguido proteger suas filhas e evitar o abuso. As autoras identificaram este aspecto como um discurso recorrente na fala das mães e chamaram a atenção para o que pode estar subjacente a isso. Isto é, a culpa relatada pelas participantes pode estar associada a um modelo materno complexo, no qual não há espaço para falhas, sendo que qualquer afastamento deste modelo padrão pode acarretar sentimentos de culpa e frustração.

Além disso, é frequente, em casos de abuso sexual intrafamiliar, história materna de abuso na infância (Hiebert-Murphy, 1998; Narvaz \& Koller, 2005; Santos \& Dell'Aglio, 2007). Entretanto, muitas vezes, estas mães podem não ter revelado os abusos sofridos ou náo ter recebido nenhum tipo de intervençáo na época em que vivenciaram esta situação. Esta informação é de extrema relevância, pois máes com história de abuso sexual na infância podem reviver as emoçóes e lembranças de suas próprias experiências ao tomarem conhecimento ou lidarem com as repercussóes do abuso de suas crianças ou adolescentes (Green, Coupe, Fernandez, \& Stevens, 1995). Em estudo realizado com mães, que assim como suas filhas foram vítimas de abuso sexual intrafamiliar na infância, Santos e Dell'Aglio (2007) verificaram que outras formas de violência se sobrepóem à experiência de abuso, revelando a repetição de um padrão de interaçóes entre os membros da família. Para estas mães romperem com este ciclo de violência torna-se necessário um retorno a sua própria infância. É importante que elas possam trabalhar lembranças 
e sentimentos relacionados a essa experiência e identificar possíveis repercussōes dessa vivência ao longo de sua vida para, assim, construir novas e diferentes formas de cuidar e ser cuidada.

\section{Propostas de intervenção psicossocial com mâes}

$\mathrm{Na}$ intervenção clínica, a inclusão das mães ou cuidadores não abusivos em acompanhamento ou atendimento psicológico tem sido uma prática aos poucos valorizada e adotada. Hunter (2006), ao discutir sobre as implicaçóes práticas no trabalho com famílias em que ocorreu o abuso sexual, destacou a necessidade de os terapeutas ajustarem suas abordagens, considerando as características do abuso, da família e, principalmente, a variabilidade do impacto para a vítima.

Estudos realizados em âmbito internacional (Corcoran \& Pillai, 2008; Costas \& Landreth, 1999; Deblinger, Stauffer, \& Steer, 2001; Machado, 2008) demonstraram os benefícios de incluir mães ou cuidadores não abusivos em atendimento psicológico a famílias em que tenha ocorrido abuso sexual. Segundo Machado (2008), que trabalha com essa temática na realidade portuguesa, dentre os principais aspectos a serem abordados na fase da intervenção com a família destacam-se: a) o rompimento da ideia de caso único; b) auxiliar os pais a compreenderem o impacto do abuso, a lidarem com suas fantasias, culpabilizaçóes e com a procura de explicaçóes; c) explicar os procedimentos legais e médicos necessários; d) orientar em relaçáo à pressáo que a família faz para que a criança esqueça ou perdoe; e) evitar tentativas de vingança por parte dos familiares; f) sensibilizar os cuidadores náo abusivos para a importância do apoio à criança; e g) auxiliar os pais a lidar com os comportamentos disfuncionais, com as perguntas da criança vítima, evitando a superproteção que poderá surgir, tendo em vista as experiências sofridas. Para King et al. (2003), a intervenção deve trabalhar as dificuldades de comunicação da família, explorando aspectos como habilidade para escutar e compartilhar problemas, superando, especificamente, a evitação de falar sobre o abuso, quando a conversa é iniciada pela própria criança.

Segundo Santos (2011), a intervenção proporciona espaço para trabalhar sentimentos ambivalentes relacionados à descoberta do abuso. Além disso, a intervenção pode reforçar a decisão de notificar o abuso, fazendo com que a pessoa se sinta segura e perceba as consequências positivas de sua atitude, orientar quanto aos encaminhamentos e trâmites que se seguem após esse momento e trabalhar as expectativas em relação ao sistema judiciário. Deve, ainda, abranger e auxiliar em questóes práticas relacionadas às dificuldades da família e da própria 
mãe, como, por exemplo, a busca de um trabalho remunerado, quando essa é financeiramente dependente do abusador. Quando as necessidades das mães são ignoradas pode-se perder uma oportunidade de beneficiar a criança (Heflin, Deblinger, \& Fisher, 2004).

Estas consideraçôes mais gerais a respeito desse tipo de intervenção têm auxiliado na elaboração de propostas de atendimento. Diferentes abordagens teóricas, algumas com enfoque psicodramático, psicanalítico e/ou sistêmico (Vecina, 2002) e outras com enfoque cognitivo-comportamental (Cohen, Deblinger, Mannarino, \& Steer, 2004; Corcoran \& Pillai, 2008; Deblinger et al., 2001; Heflin et al., 2004), têm contribuído para a idealização de propostas ou modelos de atendimento psicológico às mães ou cuidadores não abusivos de vítimas de abuso sexual.

De acordo com Corcoran e Pillai (2008), que realizaram um estudo de metaanálise sobre o tratamento psicológico envolvendo cuidadores não abusivos, há uma tendência de as intervençôes serem direcionadas para a orientação teórica cognitivo-comportamental. Os autores também verificaram que as intervençóes, frequentemente descritas nos estudos, ocorriam de forma individual ou grupal e abrangiam um total de oito a 20 sessôes separadas (crianças e adultos), ou, ainda, sessões específicas de interação das crianças com os adultos.

Deblinger et al. (2001) realizaram um estudo que comparou a eficácia do atendimento a mães de crianças abusadas sexualmente em duas modalidades: grupoterapia cognitivo-comportamental e grupoterapia de apoio. Participaram do estudo 44 mães que foram aleatoriamente separadas em grupos para o tipo de tratamento que receberiam, baseado na abordagem cognitivo-comportamental ou na terapia de apoio. Ambos os atendimentos foram conduzidos pelos mesmos terapeutas, que receberam treinamento e supervisão semanal. Ao todo foram realizadas 11 sessóes com tempo de duração de uma hora e quarenta e cinco minutos em ambas as modalidades. Na primeira sessão de cada modalidade foram solicitadas às máes informaçóes sobre elas mesmas e sobre suas crianças. Entretanto, após o primeiro encontro cada grupo direcionou seu trabalho de acordo com a abordagem proposta. No grupo de máes que receberam o atendimento baseado na perspectiva cognitivo-comportamental, aspectos como se tornarem mais apoiadoras e estratégias para manter a comunicação aberta com suas crianças foram trabalhados. No grupo que tinha a condição de comparação (grupoterapia de apoio), as participantes tinham a oportunidade de partilhar com o grupo os acontecimentos mais urgentes da semana e depois o grupo selecionava um tópico a ser discutido durante cada sessão. Os terapeutas, nesta última abordagem, tinham um papel de facilitador, garantindo que a comunicação fluísse no grupo. Os resultados indicaram a importância de oferecer, para as mães ou cuidadores de vítimas de abuso 
sexual, um ambiente terapêutico no qual possam falar sobre essa experiência e no qual possam trocar e aprender estratégias para lidar com suas crianças. A grupoterapia baseada na abordagem cognitivo-comportamental possibilitou de forma mais efetiva essa troca de orientaçóes e manejo entre as participantes sobre como lidar com determinados comportamentos das crianças vítimas, através de técnicas como o role-play e estratégia de enfrentamento cognitivo (Deblinger et al., 2001). A intervençáo pôde permitir às mães um espaço para que pudessem falar de suas angústias e medos, receber orientaçôes, bem como auxiliá-las a lidar com as repercussóes do abuso sexual de seus filhos e compreender melhor a importância da manutenção do atendimento.

No Brasil, pode-se encontrar, a partir da iniciativa de profissionais ou grupo de pesquisadores interessados na temática, algumas reflexôes e indicações para que mães ou outros familiares de referência à vítima também recebam alguma forma de acompanhamento ou atendimento psicológico (Carvalho et al., 2009; Costa, Penso, Rufini, Mendes, \& Borba, 2007; Habigzang et al., 2007; Lima \& Fonseca, 2008; Padilha \& Gomide, 2004). Recentemente, Costa, Penso e Almeida (2008) descreveram uma intervenção com famílias cujos filhos foram vítimas de abuso sexual. A intervenção proposta baseou-se no modelo de Grupo Multifamiliar, envolvendo, portanto, o atendimento grupal a quatro ou cinco famílias, variando de quatro a cinco sessões com duração de três horas cada encontro. As questōes abordadas no processo de intervenção envolveram a proteção à criança, o restabelecimento da confiança entre os membros da família, a transgeracionalidade da violência, a responsabilizaçáo dos pais, assim como o sofrimento dos membros da família diante da situação (Costa et al., 2008). As autoras enfatizaram que esta proposta de intervenção auxiliou as famílias a escutarem suas crianças.

Habigzang et al. (2007) descreveram uma experiência de intervenção com mães e cuidadores não-abusivos de vítimas de abuso sexual. A intervenção ocorreu uma vez por mês ao longo de quatro meses e foi realizada paralelamente ao grupo de atendimento das vítimas de abuso sexual. $\mathrm{O}$ atendimento proposto baseou-se na abordagem cognitivo-comportamental e teve um enfoque psicoeducativo. Foram trabalhadas questôes referentes à dinâmica do abuso, aos fatores de riscos associados, às suas repercussóes para o desenvolvimento das crianças, à construçáo de estratégias de proteção e ao fortalecimento do apoio afetivo com as vítimas. As autoras destacaram que, embora a presença destes familiares nos atendimentos não tenha sido regular, as repercussóes observadas na qualidade do apoio afetivo e pelo relato das vítimas e dos próprios participantes foram positivas.

Numa experiência de atendimento em grupo com crianças e suas mães, Santos et al. (2010) descreveram as principais etapas que envolveram estes processos tera- 
pêuticos. Especificamente em relação às características do atendimento realizado, o grupo de mães, que ocorria concomitante ao das vítimas, foi descrito como de suporte e aconselhamento, constituindo-se, também, como espaço de escuta de questóes próprias da história de cada uma das mulheres, dos papéis desempenhados e ansiedades decorrentes das próprias lembranças e/ou vivências. Durante a intervenção com as mães, as autoras destacaram a importância de ampará-las e prepará-las para as possíveis manifestaçóes comportamentais que suas filhas poderiam expressar. Os encontros foram planejados a partir da demanda das máes e dos apontamentos realizados pelas profissionais que coordenavam paralelamente o grupo das meninas. $O$ processo terapêutico envolveu quatro etapas: a) construção da identidade grupal; b) impacto da revelaçấo do abuso no sistema familiar; c) habilidades de enfrentamento relacionadas à situação abusiva; e d) fortalecimento de redes de apoio e de práticas protetivas.

Por mais diversas que sejam as propostas de intervençóes com mães e/ou famílias de vítimas de abuso sexual, Costa et al. (2009) chamaram a atenção e destacaram como fundamental, num processo de atendimento contínuo e articulado, o estabelecimento do vínculo com as famílias. Este vínculo se inicia no encaminhamento entre um serviço e outro. Além disso, destacaram a importância de orientaçóes específicas sobre como cuidar e proteger seus filhos.

Ao propor uma intervenção com as mães ou cuidadores de crianças vítimas de abuso sexual é necessário compreender que estas famílias lidam com múltiplos problemas além do abuso sexual de seus filhos e, portanto, estratégias que auxiliem suas habilidades de apoio aos seus filhos e de resolução de problemas são importantes (Malloy \& Lyon, 2006). As mães são pessoas-chave para oferecer informaçôes sobre a criança, contribuir para a avaliaçáo e promover mudanças (Ross \& O'Carroll, 2004). Não se pode minimizar sua influência no atendimento e na vida da criança ou adolescente vítima. Outro aspecto fundamental é que mesmo que, inicialmente, a mãe não acredite, duvide, ou não emita açôes de apoio a sua criança, esta deve ser mantida próxima do processo terapêutico, porque, geralmente, as mães são as responsáveis por levar a criança para o atendimento.

Em intervenções em situação de crise, pode ser necessário ampliar as sessões oferecidas à criança e/ou a sua família, pelo menos no estágio inicial do processo terapêutico (Miller \& Dwyer, 1997), tendo em vista as repercussóes que a revelação do abuso pode acarretar em todo o sistema familiar. Com sessóes mais frequentes e com o estabelecimento de uma relação de confiança entre todos, criança, família e terapeuta, as mudanças e os ajustes na rotina da família são trabalhados de forma mais contínua, fazendo com que aos poucos cada membro da família possa expressar e elaborar sua dor.

Psic. Clin., Rio de Janeiro, vol.23, N.2, P.53 - 73, 20 II 


\section{Atendimento aOs AUtores de ViolênCIA}

Para compreender o fenômeno do abuso sexual contra crianças e adolescentes é necessário focalizar todas as pessoas envolvidas nessa situação, o que significa que o suspeito por ter cometido o ato, ou o autor, também é um elemento chave nesse contexto. Para combater essa violência, a responsabilização social e penal sobre o autor da ação possui, sem dúvida, sua importância, mas há que se ter clareza de que somente a punição náo basta. $\mathrm{O}$ atendimento a este público revela-se um recurso importante para impedir novos casos de abuso.

O principal objetivo das intervenções psicológicas com abusadores é a diminuição dos níveis de reincidência (Ward \& Gannon, 2006). Este é um objetivo que nem sempre é alcançado, pois o trabalho psicológico com perpetradores tem sido avaliado como complexo e difícil. Estudos mostram que estes, em geral, negam a sua culpa frente aos fatos revelados, ou admitem que praticaram o(s) ato(s), mas minimizam as consequências; ou, ainda, admitem que aconteceu, mas culpabilizam a vítima, de tê-los provocado, por exemplo (Kennedy \& Grubin, 1992; Rogers \& Dickey, 1991; Schlank \& Shaw, 1996). Desta forma, o início do tratamento torna-se difícil, uma vez que o processo terapêutico pode ser visto como desnecessário e, até mesmo, indesejado, pois não percebem que haja algum problema a ser tratado. Alguns tratamentos têm sido dirigidos para que estes indivíduos consigam admitir sua responsabilidade frente aos atos cometidos (Marshall, 1994; Schlank \& Shaw, 1996). A assunção da responsabilidade vem sendo vista como um dos fatores que predizem um bom resultado no tratamento (Marshall, 1994).

Ligado às respostas de negação e minimização das consequências do ato de violência sexual, os homens autores desse tipo de violência podem apresentar um profundo sentimento de vergonha, o que pode ser mais um obstáculo ao tratamento psicológico (Proeve \& Howells, 2002). Ao contrário da culpa, esse sentimento em geral está associado a uma avaliação negativa do indivíduo como um todo que ocasiona uma preocupaçáo em esconder ou minimizar o comportamento danoso, pois é difícil também para o abusador se defrontar com seus próprios atos. Em geral, estes homens que possuem um sentimento forte de vergonha podem náo chegar a se conscientizar que seu comportamento tenha que ser alterado, pois sua maior preocupação está em defender a si próprio. Contudo, a vergonha também denota a preocupação com a avaliaçấo que terceiros possam fazer de seus atos. Trabalhar com este público, a partir deste último aspecto, pode ser importante para o desenvolvimento de processos de culpa. Salienta-se que a culpa refere-se ao sentimento de sentir-se mal por ter causado danos a outras pessoas, isto vincula- 
do ao desejo de reparação de tais danos, bem como à vontade de modificação do comportamento (Proeve \& Howells, 2002).

Há que se considerar também que pode haver abusadores que apresentem traços de Transtorno de Personalidade Antissocial. Características desse transtorno, tais como ausência de remorso ou falta de empatia (Harris, Rice, \& Cormier, 1991), podem dificultar que o tratamento se realize, já que, mais uma vez, o fato de ter abusado de uma criança ou adolescente não é visto como um problema pelo abusador, o que dificulta sua adesão à proposta terapêutica.

Um aspecto relevante sobre o tratamento com agressores é o foco no atendimento com adolescentes ou jovens que cometeram este tipo de violência. $\mathrm{O}$ foco nesse público é importante, uma vez que o número envolvendo meninos que ainda não chegaram à fase adulta é bastante expressivo (Worling \& Curwen, 2000). Além disso, o tratamento neste período é mais aconselhável, pois adolescentes com este tipo de comportamento apresentam uma alta probabilidade de ter problemas relacionados à violência também na fase adulta (Borduin, Henggeler, Blaske, \& Stein, 1990). O tratamento com adolescentes, em âmbito internacional, se comparado ao de adultos, pode ser considerado como mais eficaz, uma vez que o comportamento abusivo ainda não está tão cristalizado nessa fase do desenvolvimento, sendo, portanto, mais facilmente modificável (Edward \& Beech, 2004). Finalmente, outro ponto importante a ser considerado sobre o tratamento voltado a adolescentes que cometeram agressão: o fato de uma parcela significativa destes jovens apresentar problemas em outras áreas da vida, tais como famílias com alto nível de violência, problemas escolares e com os pares (Borduin et al., 1990; Worley $\&$ Curwing, 2000). Desta forma, é necessário estar atento a aspectos do entorno do adolescente de modo a compreender características e fatores de risco presentes no seu contexto e nas suas relaçóes e tentar melhorá-las, cuidando do adolescente e não o concebendo apenas como agressor.

\section{Propostas de intervençáo psicossocial Com aUtores de VIOLÊNCIA}

Atualmente, vários são os tratamentos utilizados para diminuir o risco de uma nova recaída. Eles vão desde o tratamento com medicamentos (psicofármacos e reguladores hormonais) usados isoladamente ou combinados com psicoterapia, ou ainda intervençóes psicológicas realizadas sem o auxílio destes medicamentos. Podem ser realizadas até intervençôes cirúrgicas, como a castração (Marshall \& Laws, 2003b).

Psic. Clin., Rio de Janeiro, vol.23, N.2, P.53 - 73, 20 II 
Vários são os aspectos a serem trabalhados durante o processo de psicoterapia. Alguns deles, tais como a aceitação da responsabilidade e a vergonha, já foram citados. Outro é o treinamento empático. Ou seja, trabalhar junto a estes indivíduos a capacidade de perceber, através dos comportamentos das vítimas no momento do abuso, que este ato é imensamente danoso para elas (Hanson, 2003; Pithers, 1999). Este trabalho pode ser feito de muitas maneiras, como, por exemplo, colocar os autores da violência em contato com cartas de vítimas. A seguir o treinamento para controle dos impulsos sexuais desviantes deve ser realizado. Os indivíduos são estimulados a não se colocar em situações de risco, nas quais esse controle pode ser mais difícil, tais como ficar sozinho com uma criança, no caso de homens que têm desejo sexual por crianças (Beech, Fischer, \& Beckett, 1998).

Há dois conjuntos de técnicas de intervenção comportamental voltadas para homens diagnosticados com parafilias (transtornos sexuais), grupo no qual se encontra uma boa parte dos agressores sexuais. Uma é o contracondicionamento; a segunda é o condicionamento aversivo (Brotto \& Klein, 2007). O primeiro conjunto de técnicas baseia-se no princípio de trocar respostas negativamente condicionadas por respostas positivas. No caso de agressores sexuais, isto significa transformar os interesses sexuais parafílicos em interesses sexuais não-parafílicos. Já as técnicas que compreendem o segundo grupo, a terapia baseada em estímulos aversivos, consistem basicamente em parear repetidamente estímulos aversivos aos comportamentos indesejáveis, fazendo com que os comportamentos indesejáveis se associem a tais estímulos (Brotto \& Klein, 2007).

As técnicas descritas focalizam, sobretudo, a modificação do comportamento. A terapia cognitivo-comportamental, por sua vez, assume que os padróes de pensamento dos agressores sexuais são disfuncionais, assim as técnicas cognitivas têm como foco a modificação de padróes de pensamento para resolução de problemas emocionais e comportamentais (Brotto \& Klein, 2007). Duas técnicas comuns são a reestruturação cognitiva e o treinamento de empatia.

As técnicas comportamentais e cognitivo-comportamentais são as mais citadas, pois englobam os tratamentos mais usados no que diz respeito ao tratamento de abusadores sexuais. As terapias de base psicodinâmica não são muito divulgadas, náo mostram resultados táo positivos e são de mais difícil avaliação. Outros tipos de tratamento baseados em outras escolas psicológicas também não são muito relatados (Marshall \& Laws, 2003a). A eficácia dos tratamentos para este público tem sempre como critério a diminuição nos índices de reincidência. Alguns estudos expostos a seguir demonstram os melhores resultados da terapia cognitivo-comportamental em relação a outros tipos de tratamento. McGrath, Hoke e Vojtisek (1998) compararam os resultados na reincidência em homens 
alocados em três grupos: 71 participantes receberam tratamento cognitivo-comportamental, 32 foram tratados de forma menos diretiva que essa abordagem e 19 não receberam tratamento. Os resultados demonstraram que o grupo que se submeteu à terapia cognitivo-comportamental mostrou maior diminuição nos índices de reincidência.

Por outro lado, Marques et al. (2005) realizaram um estudo que comparou três grupos de homens que cometeram abuso sexual. Eles foram aleatoriamente alocados em cada um dos grupos. Um grupo já estava em liberdade e foi tratado com técnicas de uma abordagem denominada prevenção de recaída, baseada em técnicas da terapia cognitivo-comportamental. Os outros dois grupos eram egressos de instituiçóes prisionais que não receberam tratamento. Os três grupos foram acompanhados durante um período de oito anos: o primeiro grupo oito anos após o tratamento e os outros dois grupos oito anos após terem saído da prisão. Os resultados demonstraram que não houve diferença significativa nos índices de reincidência entre os três grupos. Contudo, mesmo sem haver diferença em termos estatísticos, aqueles que participaram do tratamento apresentaram menores índices de reincidência do que aqueles que náo foram tratados.

Além do foco e das técnicas utilizadas na intervenção, estudos têm discutido sobre a faixa etária do agressor, suas características de personalidade e tipo de interação sexual, que envolvia suas açóes, como aspectos importantes de serem considerados ao propor atendimento (Edward \& Beech, 2004; Miranda \& Corcoran, 2000). Observar esses aspectos pode auxiliar os profissionais a ajustarem os objetivos da proposta de atendimento, bem como avaliar potenciais riscos, como, por exemplo, abandono do tratamento ou reincidência, principalmente quando se trabalha com adolescentes (Edward \& Beech, 2004).

De uma maneira geral, quanto à eficácia dos tratamentos, Lösel e Schmucker (2005) relataram que os resultados ainda não são conclusivos. Existe uma tendência de que a terapia com homens que cometeram agressáo sexual deve ser dirigida a todos os aspectos de sua vida com o objetivo de melhorar sua qualidade de vida como um todo, e não trabalhar, especificamente, com as cogniçôes ou distorçôes cognitivas inerentes a essa problemática (McMurran \& Ward, 2004). Contudo, pouca importância é dada a este tipo de enfoque e a maioria dos tratamentos focaliza apenas o manejo do risco e não a melhora da qualidade de vida e assim, por consequência, a diminuição no número de atos de violência cometidos por esses homens (McMurran \& Ward, 2004).

No Brasil, há poucas iniciativas para o tratamento de pessoas que cometeram agressão sexual. A maioria dos relatos, textos ou artigos sobre esse público trata das características psicológicas (Esber, 2008; Magalhães, 2003; Moura, 2007).

Psic. Clin., Rio de Janeiro, vol.23, N.2, P.53 - 73, 20 II 
Entretanto, cabe destacar a experiência de Vecina (2002), que atendeu 26 autores de violência contra crianças e adolescentes, dentre os quais 13 haviam cometido violência sexual. A autora destacou que o tratamento teve como ponto de partida a não-estigmatização dos abusadores como irrecuperáveis, considerando que um trabalho psicoterapêutico pode ser útil numa tentativa de reconstrução de vários aspectos de suas vidas. Assim, não se deve ter como objetivo apenas o controle dos impulsos que estariam associados com a prática da violência. Este estudo constatou pontos já verificados em outras experiências de tratamento, tais como a negação dos atos cometidos, ocasionada tanto pelo envolvimento legal quanto pela questão da defesa psíquica. Relatou, ainda, que os pacientes desse tipo testam a equipe quanto a sua disponibilidade, minimizam as consequências das violências praticadas, tentam se aliar ao terapeuta contra aqueles que consideram que os perseguem, entre outros mecanismos. Por outro lado, Vecina (2002) destacou aspectos novos quando relatou o uso de conceitos religiosos e morais pelos autores das violências. Segundo a autora, esses conceitos pareceram ser usados como uma forma de encobrir as partes "más" de si e dos outros. Vecina (2002) também ressaltou o papel que o encaminhamento compulsório tem para a terapia: embora os indivíduos compareçam ao tratamento sem desejo de realizá-lo, essa obrigatoriedade proporciona o contato com a terapia. Sem o fator da compulsoriedade, dificilmente os autores de violência se submeteriam a esse tipo de processo.

Vecina (2002) afirmou que algumas posturas por parte da equipe multidisciplinar são necessárias para o manejo dos autores de violência sexual: deixar claros os objetivos do tratamento; oferecer suporte legal de modo a evitar fugas e desistências; compreender os motivos da negação e trabalhar com o desmonte dela; estabelecer limites e regras para o atendimento. Deve ainda reconhecer o sofrimento e ter empatia pelas vivências do paciente (seja da história passada ou atual), bem como pelo segredo, mobilizar angústia para que haja reconhecimento da necessidade de mudança, evitar a postura "policialesca", ou seja, fugir do tom acusatório, evitar a banalizaçâo da violência, entre outros (Vecina, 2002). Em suma, a autora relatou que os pacientes devem ser estimulados a assumir as responsabilidades diante das vitimizações cometidas, contudo sem tomar para si uma identidade estanque que se identifique apenas com essa faceta. Ou seja, a psicoterapia deve ajudá-los a reconhecer a gravidade de seus atos, porém deve proporcionar uma visão de possibilidade de mudança e não um reforço da estigmatizaçáo dos pacientes. Esse trabalho fornece sugestóes importantes de como lidar com esse tipo de público, porém não apresenta avaliaçôes da intervenção realizada.

Em pesquisa mais recente acerca dos programas de atendimento para homens que cometeram violência sexual, Toneli (2007) e sua equipe verificaram que, no 
Brasil até esse ano, só havia dois programas voltados aos autores de violência. Ambos os serviços estáo localizados na cidade do Rio de Janeiro. O objetivo inicial da pesquisa era mapear programas de atendimento voltados a autores de violência sexual na América Latina. Contudo, foi verificada a escassez destes programas e o levantamento acabou por se focar nos programas de atendimento a autores de violência de uma maneira geral, sobretudo a violência física. Toneli (2007) afirmou que, de uma maneira geral, os programas na América Latina eram iniciativas da sociedade civil, que se mantinham com financiamentos de agências internacionais e atendiam seus públicos sob a forma de grupos, principalmente por profissionais da área "psi". Foi também observado que os programas não possuíam sistemas de avaliação de resultados bem organizados, sendo que, quando havia alguma avaliação, esta era feita pelo próprio autor de violência, que identificava quais os benefícios que a participação no grupo trouxera para sua vida (Toneli, 2007).

Dos programas específicos no Brasil, um se volta ao atendimento de homens que cometeram algum tipo de violência contra mulher e por isso não será descrito com mais detalhes. $\mathrm{O}$ outro programa atende tanto as vítimas (adultas, crianças ou adolescentes) quanto os autores de qualquer tipo de violência. A abordagem psicológica que embasa o trabalho é a psicanálise, embora os responsáveis pelo programa afirmem que náo é feito um trabalho psicanalítico propriamente dito, pois: não há pagamento pela consulta, o setting terapêutico difere do da psicanálise clássica e o paciente não "fala do que vier à cabeça", com o foco do tratamento sendo especificamente a violência. Segundo os responsáveis pelo programa, a adesão dos autores de violência ao tratamento é efetiva (Toneli, 2007). Neste trabalho também não há relato sobre avaliação da eficácia do tratamento.

\section{Consideraçóess finais}

A preocupação com o atendimento a vítimas de abuso sexual evoluiu no Brasil. Em termos de políticas públicas destaca-se o Plano Nacional de Enfrentamento da Violência Sexual Infanto-Juvenil, que estabeleceu um conjunto de diretrizes. Estas possibilitaram a ação técnica, política e financeira para lidar com esse problema. Baseado nesse plano nacional foi criado o Programa de Açóes Integradas e Referenciais de Enfrentamento da Violência Sexual Infanto-Juvenil no Território Brasileiro (PAIR) que, desde 2002, tem se constituído uma metodologia de articulação de políticas e intervenção de redes (Amorim, Contini, \& Meza, 2008; Brasil, 2002).

Os programas previstos no plano nacional devem se voltar ao atendimento de todos os envolvidos nos casos de abuso contra crianças e adolescentes. Mas, como

Psic. Clin., Rio de JANeiro, vol.23, N.2, P.53 - 73, 20 II 
as iniciativas ainda são recentes, observa-se que as vítimas são, ainda, o principal foco de atenção desses serviços. Contudo, como já foi visto ao longo deste artigo, o atendimento a mães das vítimas e aos autores da violência é também fundamental, pois no primeiro caso o apoio às mães incide diretamente nos resultados com as crianças, além de aliviar o sofrimento destas. No caso dos homens que praticaram atos de abuso, o tratamento é necessário, pois ele pode contribuir para a diminuição da reincidência, evitando que haja novas vítimas.

Mesmo que não se tenham dados conclusivos quanto às formas e possibilidades de tratamento dos autores de violência sexual, considera-se que é importante que os profissionais estejam capacitados para este tipo de intervenção e que deixem de lado o rótulo de pessoas irrecuperáveis, frequentemente atribuído a estas pessoas.

No Brasil ainda são poucas as situações em que se identificam políticas públicas ou programas de intervençôes mais organizados para lidar com as mães das vítimas e com os homens que cometeram abuso sexual. Além disso, os estudos brasileiros sobre estes tipos de intervenção ainda são escassos e iniciais, embora esteja se observando um maior interesse dos pesquisadores tanto em relação às mães das vítimas quanto aos autores das violências.

Em relação ao tratamento ou acompanhamento psicológico às mães das vítimas e aos abusadores, os desafios são constantes e vários aspectos ainda precisam ser considerados. Há consenso na literatura sobre a importância de oferecer alguma forma de acompanhamento, não apenas social, mas também psicológico, a estes dois públicos. Um dos aspectos a serem observados, independentemente da linha teórica adotada, está relacionado à construção do vínculo entre profissionais (terapeutas) e paciente, além da motivaçáo para iniciar e dar continuidade ao tratamento pessoal ou da própria criança ou adolescente vítima. Nessa perspectiva, o tempo de espera para o início do acompanhamento pode ser um fator negativo, principalmente quando há indicação de intervenção em momentos de crise, como é o caso das situaçóes que envolvem abuso sexual.

No caso dos autores de violência há ainda outros aspectos que dificultam a efetivação de uma proposta mais abrangente. $\mathrm{O}$ interesse pelo tema pode estar sendo atravessado pela dificuldade em lidar com estas pessoas, já que os atos de agressáo sexual são vistos como hediondos e desumanos pela sociedade em geral. Também por isso parece haver escassez de pessoas com treinamento específico. É necessário que o profissional que trabalha nessa área esteja muito atento às suas posturas para não incorrer numa posição policialesca, que procura acusar e encontrar evidências da culpa pelos atos de abuso. A pouca atenção dada pelos setores governamentais e a consequente falta de investimento financeiro na área são outros problemas (Toneli, 
2007). O envolvimento legal certamente pode contribuir para a dificuldade em realizar atendimentos a esse público. A obrigatoriedade do tratamento pode tanto proporcionar o contato com a terapia, como afirma Vecina (2002), e ao mesmo tempo pode ser um obstáculo, uma vez que aquelas pessoas mais resistentes podem sentir o processo terapêutico como absolutamente indesejável. A falta de avaliação dos resultados dos poucos programas existentes no Brasil também é um ponto de preocupação, pois, para que estes programas possam receber verbas públicas, eles precisam se mostrar efetivos. A ausência da avaliação é, portanto, um obstáculo.

O abuso sexual contra crianças e adolescentes é um problema que requer uma maior atenção. Náo envolve apenas a família e suas relaçôes, mas a sociedade como um todo. Trata-se de uma violência que pode ter conexóes com outras, como a exploração sexual e o tráfico de crianças e adolescentes, por exemplo. Para enfrentar esse problema não bastam apenas boas intençôes, fazem-se necessárias açóes, conforme salientam Carvalho et al. (2009). Açôes que se pautem por uma efetiva integração intersetorial segurança pública, saúde, educação e justiça (Campos et al., 2005). É preciso desatar os nós, ampliar a compreensão do fenômeno, refletir sobre suas causas, sensibilizar para a dor das vítimas e de seus familiares e perceber que este problema não diz respeito apenas a quem o vivencia, ou aos profissionais e pesquisadores que com ele lidam diariamente. É um problema de todos que lutam por uma sociedade livre de violência.

\section{REFERÊNCIAS}

Amorim, S. M. F., Contini, M. L. J., \& Meza, E. R. (2008). Avaliação do processo de implantação do PAIR. Campo Grande: Editora da Universidade de Minas Gerais.

Araújo, M. F. (2002). Violência e abuso sexual na família. Psicologia em Estudo, 7(2), 311.

Beech, A., Fisher, D., \& Beckett, R. (1998). Step 3: an evaluation of the Prison Sex Offender Treatment Programme. Relatório Técnico de Pesquisa.

Borduin, C. M., Henggeler, S. W., Blaske, D. M., \&. Stein, R. J. (1990). Multisystemic treatment of adolescent sexual offenders. International Journal of Offender: Therapy and Comparative Criminology, 3(1), 105-113.

Brasil (2002). Notificação de maus-tratos contra crianças e adolescentes pelos profissionais de saúde: Um passo a mais na cidadania em saúde. Brasília: Ministério da Saúde.

Brotto, L. A., \& Klein, C. (2007). Sexual and gender identity disorders. In: M. Herse, S. M. Turner, \& D. C. Birdel (Orgs.). Adult Psychopathology and Diagnosis (pp. 504-570). New Jersey: Jonh Wiley and Sons.

Psic. Clin., Rio de Janeiro, vol.23, N.2, P.53 - 73, 20 II 
Campos, M. A. M. R., Schor, N., Anjos, R. M. P., Laurentiz, J. C., Santos, D. V., \& Peres, F. (2005). Violência sexual: integração saúde e segurança pública no atendimento imediato à vítima. Saúde e Sociedade, 14(1), 101-109.

Carvalho, Q. C. M., Galvão, M. T. G., \& Cardoso, M. V. L. M. L. (2009). Abuso sexual infantil: percepção de mães em face do abuso sexual de suas filhas. Revista Latino-Americana de Enfermagem, 17(4), 501-506.

Cohen, J. A., Deblinger, E., Mannarino, A. P., \& Steer, R. A. (2004). A multisite randomized controlled trial for children with sexual abuse-related PTSD symptoms. Journal of American Academic Child and Adolescent Psychiatry, 43(4), 393-402.

Corcoran, J., \& Pillai, V. (2008). A meta-analysis of parent involved treatment for child sexual abuse. Research on Social Work Pratice, 18(5), 453-464.

Costa, L. F., Almeida, T. M. C, Ribeiro, M. A., \& Penso, M. A. (2009). Grupo multifamiliar: espaço para a escuta de famílias em situação de abuso sexual. Psicologia em Estudo, 14(1), 21-30.

Costa, L. F., Penso, M. A., \& Almeida, T. M. C. (2008). O grupo multifamiliar: uma intervenção no abuso sexual infantil e adolescente. In: L. F. Costa, \& H. G. D. Lima, de (Orgs). Abuso sexual: A justiça interrompe a violência (pp. 35-52). Brasília: Líber Livro.

Costa, L. F., Penso, M. A., Rufini, B. R., Mendes, J. A. A., \& Borba, N. F. (2007). Família e abuso sexual: silêncio e sofrimento entre a denúncia e a intervenção terapêutica. Arquivos Brasileiros de Psicologia, 59(2), 245-255.

Costa, L., Souza, L. R. P., Castanha, N., \& Lima, T. S. (2009). Disque 100: cem mil denúncias e um retrato da violência sexual infanto-juvenil. Brasília: Secretaria Especial de Direitos Humanos.

Costas, M., \& Landreth, G. (1999). Filial therapy with nonoffending parents of children who have been sexually abused. International Journal of Play Therapy, 8(1), 43-66.

Deblinger, E., Stauffer, L. B., \& Steer, R. A. (2001). Comparative efficacies of supportive and cognitive behavioral group therapies for young children who have been sexually abused and their nonoffending mothers. Child Maltreatment, 6(4), 332-343.

Edward, R., \& Beech, A. (2004). Treatment programmes for adolescents who commit sexual offenses: Dropout and recidivism. Journal of sexual aggression, 10, 101-115.

Elliot, A. N., \& Carnes, C. N. (2001). Reactions of nonoffending parents to the sexual abuse of their child: A review of the literature. Child Maltreatment, 6(4), 314-331.

Esber, K. M. (2008). Autores de violência sexual contra crianças e adolescentes: um estudo a partir da teoria sócio-histórica. (Dissertação de Mestrado). Programa de Pós-Graduação Stricto Sensu em Psicologia, Universidade Católica de Goiás, Goiânia, GO.

Faleiros, E. (2003). Abuso sexual contra crianças e adolescentes: os (des)caminhos da denúncia. Brasília: Presidência da República, Secretaria Especial dos Direitos Humanos. 
Furniss, T. (2002). Abuso sexual da criança: uma abordagem multidisciplinar: manejo, terapia e intervenção legal integrados. (M. A. V. Veronese, Trad.). Porto Alegre: Artes Médicas.

Green, A. H., Coupe, P., Fernandez, R., \& Stevens, B. (1995). Incest revisited: delayed Pos-Traumatic Stress Disorder in mothers following the sexual abuse of their children. Child Abuse \& Neglect, 19(10), 1275-1282.

Habigzang, L. F., Koller, S. H., Azevedo, G. A., \& Machado, P. X. (2005). Abuso sexual infantil e dinâmica familiar: aspectos observados em processos jurídicos. Psicologia: Teoria e Pesquisa, 21(3), 341-348.

Habigzang, L. F., Stroeber, F., Corte, F. D., Hatzenberger, R., Cunha, R. C., Ramos, M., \& Koller, S. H. (2007). Integrando os cuidadores, a rede e os terapeutas: potencializando a melhora clínica de crianças e adolescentes vítimas de abuso sexual. In: M. L. P. Leal, M. F. P. Leal, \& Libório, R. M. C (Orgs.). Tráfico de pessoas e violência sexual (pp. 263274). Brasília: Violes/Ser/Universidade de Brasília.

Hanson, R. K. (2003). Empathy deficits of sexual offenders: a conceptual model. Journal of Sexual Aggression, 9, 13-23.

Harris, G. T., Rice, M. E., \& Cormier, C. A. (1991). Psychopathy and violent recidivism. Law and Human Behaviour, 15, 625-637.

Heflin, A. H., Deblinger, E., \& Fisher, C. D. (2004). Abuso sexual da criança. In: F. M. Dattilio, \& A. Freeman (Orgs.). Estratégias cognitivo-comportamentais de intervenção em situaçóes de crise (pp. 144-166). Porto Alegre: Artmed.

Hiebert-Murphy, D. (1998). Emotional distress among mothers whose children have been sexually abused: The role of a history of child sexual abuse, social support, and coping. Child Abuse or Neglect, 22(5), 423-435.

Hunter, S. V. (2006). Understanding the complexity of child sexual abuse: a review of the literature with implications for family counseling. The Family Journal, 14(4), 349358.

Kennedy, H. G., \& Grubin, D. H. (1992). Patterns of denial in sex offenders. Psychological Medicine: A Journal of Psychiatric Research and the Allied Sciences, 22(1), 191-196.

King, N. J., Heyne, D., Tonge, B. J., Mullen, P., Myerson, N., Rollings, S., \& Ollendick, T. H. (2003). Sexually abused children suffering from posttraumatic stress disorder: Assessment and treatment strategies. Cognitive Behaviour Therapy, 32(1), 2-12.

Koller, S. H., \& De Antoni, C. (2004). Violência intrafamiliar: uma visão ecológica. In: S. H. Koller (Org.). Ecologia do desenvolvimento humano (pp. 293-310). São Paulo: Casa do Psicólogo.

Krug, E. G., Dahlberg, L. L., Mercy, J. A., Zwi, A. B., \& Lozano, R. (2002). World report on violence and health. Genebra: World Health Organization - WHO. Retirado de: the World Wide Web: http://whqlibdoc.who.int/hq/2002/9241545615.pdf.

Psic. Clin., Rio de JANeiro, vol.23, N.2, P.53-73, $201 \mathrm{I}$ 
Lima, H. G. D., \& Fonseca, M. A. M. (2008). O estudo psicossocial e a "nova justiça". In: L. F. Costa, \& H. G. D. Lima (Orgs.). Abuso sexual: A justiça interrompe a violência (pp. 19-32). Brasília: Líber Livro Editora.

Lösel, F., \& Schmucker, M. (2005). The effectiveness of treatment for sexual offenders: a comprehensive meta-analysis. Journal of Experimental Criminology, 1(1), 117-146.

Machado, C. (2008). Abuso sexual de crianças. In: C. Machado, \& R. A. Gonçalves (Orgs.). Violência e vitimas de crimes - volume 2: crianças (pp. 41-93). Coimbra: Quarteto.

Magalhāes, V. E. de (2003). Criminosos sexuais: um perfil de sujeitos condenados por crimes sexuais (Dissertação de Mestrado). Mestrado em Sexologia, Universidade Gama Filho, Rio de Janeiro, RJ.

Malloy, L. C., \& Lyon, T. D. (2006). Caregiver support and child sexual abuse: why does it matter? Journal of Child Sexual Abuse, 15(4), 97-103.

Marques, J. K., Wiederanders, M., Day, M. D., Nelson, C., \& Ommeren, A. V. (2005). Effects of a relapse prevention program on a sexual recidivism: final results from California's Sex Offender Treatment and Evaluation Project (SOTEP). Sexual Abuse: $A$ Journal of Research and Treatment, 17(11), 79-107.

Martins, C. B. G., \& Jorge, M. H. P. M. (2009). A violência contra crianças e adolescentes: características epidemiológica dos casos notificados aos conselhos tutelares e programas de atendimento em município do sul do Brasil, 2002 e 2006. Epidemiologia e Serviços de Saúde, 18(4), 315-334.

Marshall, W. L. (1994). Treatment effects on denial and minimization in incarcerated sex offenders. Behaviour Research and Therapy, 32(5), 559-564.

Marshall, W. L., \& Laws, D. R. (2003a). A brief history of behavioral and cognitive behavioral approaches to sexual offenders: part 1. Early developments. Sexual Abuse: $A$ Journal of Research and Treatment, 15(2), 73-92.

Marshall, W. L., \& Laws, D. R. (2003b). A brief history of behavioral and cognitive behavioral approaches to sexual offender treatment: part 2. The modern era. Sexual Abuse: A Journal of Research and Treatment, 15(2), 93-120.

McGrath, R. J., Hoke, S. E., \& Vojtisek, J. (1998). Cognitive-behavioral treatment of sex offenders. Criminal Justice and Behavior, 25(2), 203-225.

McMurran, M., \& Ward, T. (2004). Motivating offenders to change in therapy: an organizing framework. Legal and Criminological Psychology, 9, 295-311.

Miller, R., \& Dwyer, J. (1997). Reclaiming the mother-daughter relationship after sexual abuse. Family Therapy, 18(4), 194-203.

Miranda, A. O., \& Corcoran, C. L. (2000). Comparison of perpetration characteristics between male juvenile and adult sexual offenders: preliminary results. Sexual Abuse: $A$ Journal of Research and Treatment, 12, 179-188.

Psic. Clin., Rio de Janeiro, vol.23, N.2, P.53-73, 20 II 
Moura, A. da S. (2007). A criança na perspectiva do abusador sexual (Dissertação de Mestrado). Programa de Pós-Graduação em Psicologia, Universidade Federal do Rio Grande do Sul, Porto Alegre, RS.

Narvaz, M. G., \& Koller, S. H. (2005). Reflexóes sobre o atendimento de meninas e mulheres vítimas de violência. Novas Abordagens em Direitos Humanos: enfrentamento à violência, 1(1), 34-42.

Padilha, M. G. S., \& Gomide, P. I. C. (2004). Descrição de um processo terapêutico em grupo para adolescentes vítimas de abuso sexual. Estudos em Psicologia, 9(1), 53-61.

Pelisoli, C. L., \& Dell'Aglio, D. D. (2007). A percepção de família em vítimas de abuso sexual intrafamiliar: estudo de caso. Arquivos Brasileiros de Psicologia, 59(2), 256-269.

Pintello, D., \& Zuravin, S. (2001). Intrafamilial child sexual abuse: predictors of postdisclosure maternal belief and protective action. Child Maltreatment, 6(4), 344-352.

Pithers, W. D. (1999). Empathy: definition, enhancement, and relevance to the treatment of sexual abusers. Journal of Interpersonal Violence, 14(3), 257-284.

Proeve, M., \& Howells, K. (2002). Shame and guilt in child sexual offenders. International journal of offender therapy and comparative criminology, 46(6), 657-667.

Rogers, R., \& Dickey, R. (1991). Denial and minimization among sex offenders. Sexual Abuse: A Journal of Research and Treatment, 4(1), 49-63.

Ross, G., \& O'Carroll, P. (2004). Cognitive behavioural psychotherapy intervention in childhood sexual abuse: identifying news directions from the literature. Child Abuse Review, 13, 51-64.

Santos, S. S. (2011). Uma análise do contexto de revelação e notificação do abuso sexual: a percepção de máes e de adolescentes vítimas (Tese de Doutorado). Programa de Pós-Graduação em Psicologia, Universidade Federal do Rio Grande do Sul, Porto Alegre, RS.

Santos, S. S., Borges, J. L., Ruschel, A. E., Padilha, J. I. H., Silva, S. C., \& Dell'Aglio, D. D. (2010). Intervenção na situação de abuso sexual: uma experiência de grupo com crianças e seus cuidadores. In: C. S. Hutz (Org.). Avanços em psicologia comunitária e intervençóes psicossociais (pp. 119-163). São Paulo: Casa do Psicólogo.

Santos, S. S., \& Dell'Aglio, D. D. (2007). Multigeracionalidade da violência: um estudo sobre mães de meninas vítimas de abuso sexual. In: M. L. P. Leal, M. F. P. Leal, \& R. M. C. Libório (Orgs.). Tráfico de pessoas e violência sexual (pp. 191-211). Brasília: Violes/Ser/Universidade de Brasília.

Santos, S. S., \& Dell'Aglio, D. D. (2009). Revelação do abuso sexual infantil: reaçóes maternas. Psicologia: Teoria e Pesquisa, 25(1), 85-92.

Schlank, A. M., \& Shaw, T. (1996). Treating sexual offenders who denied their guilt: a pilot study. Sexual Abuse: A Journal of Research and Treatment, 8(1), 17-23.

Psic. Clin., Rio de Janeiro, vol.23, N.2, P.53-73, $201 \mathrm{I}$ 
Toneli, M. J. F. (2007). Violência sexual e saúde mental: análise dos programas de atendimento a homens autores de violência sexual. Relatório final de pesquisa. Universidade Federal de Santa Catarina. Florianópolis, Brasil.

Vecina, T. C. C. (2002). Do tabu à possibilidade de tratamento psicossocial: um estudo reflexivo da condiçấo de pessoas que vitimizaram crianças e adolescentes. In: D. C. A. Ferrari, \& T. C. C. Vecina (Orgs.). O fim do silêncio na violência familiar. Teoria e prática (pp. 201-212). São Paulo: Summus Editorial.

Ward, T., \& Gannon, T. A. (2006). Rehabilitation, etiology, and self-regulation: the comprehensive good lives model of treatment for sexual offenders. Aggression and Violent Behavior, 11(1), 77-94.

Worling, J. R., \& Curwen, T. (2000). Adolescent sexual offender recidivism: success of specialized treatment and implications for risk prediction. Child Abuse \& Neglect, 24(7), 965-982.

\section{Nota}

1 Trabalho desenvolvido com o apoio do Conselho Nacional de Desenvolvimento Científico e Tecnológico (CNPq).

Recebido em 28 de março de 2011 Aceito para publicação em 30 de junho de 2011 